\title{
DO SUPLÍCIO DE TÂNTALO À GULA SELVAGEM: EVOCAÇÕES DOS CONTOS DE Guy de Maupassant
}

Ana Luiza Reis Bedē*

(D) https://orcid.org/0000-0001-6815-6501

Como citar este artigo: BEDÊ, A. L. R. Do suplício de tântalo à gula selvagem: evocações dos contos de Guy de Maupassant. Todas as Letras - Revista de Lingua e Literatura, São Paulo, v. 22, n. 2, p. 1-12, maio/ago. 2020. DOI 10.5935/19806914/eLETLT2011815

Submissão: setembro de 2018. Aceite: março de 2019.

Resumo: Nos contos de Guy de Maupassant, as descrições do almoço, jantar, ceias e piqueniques desencadeiam episódios fundamentais nas narrativas. Elas propõem, via de regra, elementos para a reflexão sobre as personagens, suas angústias, seus desejos e receios. Evocam, ainda, suas intenções ocultas e suas manobras para manipular o outro. Para além do efeito realista visado pelo autor, como, aliás, por muitos escritores da segunda metade do século XIX, tudo o que se passa "à mesa", nas histórias do contista normando, merece um questionamento atento do leitor. Neste artigo, refletimos sobre o cálculo, a duplicidade, a constante simulação que norteiam os costumes e as atitudes de camponeses, burgueses e aristocratas a partir dos episódios envolvendo refeições. Abordaremos contos de diferentes temáticas, enfatizando, porém, os textos consagrados à Guerra Franco-Prussiana, de 1870.

Palavras-chave: Guy de Maupassant. Refeições. Contos. Descrição. Guerra Franco-Prussiana. 


\section{INTRODUÇÃO - À ESPERA DOS CONVIVAS}

$\mathbf{P}$ orcelana de Sèvres, talheres de prata, taças de cristal, ovos de faiança, terrinas que duram várias gerações e toalhas impecáveis. Salões decorados com tapeçarias de Flandres, poltronas imperiais, lustres suntuosos, candelabros, retratos de família e quadros antigos completam o cenário das refeições de inúmeras narrativas de Maupassant.

Se fôssemos inventariar as diversas iguarias servidas ao longo de seus mais de 300 contos, descobririamos um rol magnífico, indo das ostras, dos lagostins e camarões, às perdizes, aos patos, aos coelhos, aos cordeiros, aos frangos, aos porcos, preparados de diferentes maneiras: assados, refogados, confit ${ }^{1}$, em geral acompanhados, entre muitos outros legumes e condimentos, de azeitonas, cebolas, couves e cenouras. Os tradicionais chouriços, patês e foie gras também fazem parte desse rico cardápio.

Não falta espaço para a cozinha típica da Normandia, indo dos guisados aos potages, sopas e saladas. Regalamo-nos com os fricots (tipo de mexidão) com batatas e toucinhos. A propósito: "A gulodice é um dos pilares do mundo de Maupassant, e evidentemente, da cozinha normanda" (BROCHIER, 1993, p. 55).

Dispostos de forma sofisticada ou simples, esses pratos suculentos são servidos regados por sidra, champanhe e vinhos de diversas procedências. Além dos encontros acompanhados de, dependendo do status social, aguardente, vermute, cerveja, conhaque, vinho do Porto ou licores.

Um crítico cioso de classificar escritores segundo programas estéticos determinados apontará a obsessão do autor de "Bola de Sebo" em relação aos pormenores relativos às refeições como marca característica dos movimentos realista e naturalista que floresceram na França na segunda metade do século XIX.

Se há, de um lado, preocupação com o "efeito realista" em Maupassant, afinal, em seu luminoso ensaio "Le Roman” (MAUPASSANT, 1987, p. 703-715), reflete sobre a construção da verossimilhança que norteou boa parte de sua obra, de outro, as cenas envolvendo as delícias (ou repugnâncias) relativas aos alimentos sugerem intrincadas relações entre as personagens, traduzindo, não raro, um pessimismo exacerbado.

É pouco alentadora a visão do ser humano vislumbrada ao longo das narrativas de Maupassant. O filósofo alemão Schopenhauer, verdadeira coqueluche no período, teve influência considerável na obra do contista normando. Nesse sentido, discordamos de Marc Smeets (2007) quando afirma que o contato com os textos de Schopenhauer por muitos escritores da segunda metade do século XIX, como Maupassant e Huysmans, ocorreu por meio do livro de Jean Bourdeau, Arthur Schopenhauer, Pensées: maximes et fragments, ou seja, de forma superficial e redutora.

Essa compilação de textos tornou-se um breviário para a geração fin-de-siècle. Isso, porém, mereceria outro artigo. Além da marcada presença do filósofo alemão, o pessimismo e a visão de mundo de Maupassant também são tributários da guerra de 1870, sobre a qual comentaremos, de forma sumária, adiante.

1 Confit é a técnica de cozimento de alimentos em gordura, utilizando-se baixa temperatura e tempo prolongado. 


\section{O PRAZER DA BOA MESA: CILADAS E TORTURAS}

Provocar intencionalmente o mal a outrem para obter vantagens não costuma suscitar problemas de consciência nos camponeses das histórias de Maupassant. Um bom exemplo da hipocrisia nas relações está no conto "Le Petit Fût" (MAUPASSANT, 1979, p. 77-82), publicado no "Le Gaulois", em 1884, que obteve um sucesso retumbante e foi considerado uma das melhores criações do autor.

Nessa narrativa, a avara e septuagenária Magloire continuava trabalhando, apesar da idade, na fazenda onde vivia desde a infância. O albergueiro Chicot, interessado em adquirir o local e não conseguindo vencer a resistência da proprietária, propõe-lhe dar 30 escudos por mês para que ele herdasse a fazenda após sua morte. Enquanto vivesse, Magloire poderia permanecer tranquilamente em sua residência. A camponesa aceitou o contrato, mas solicitou a mensalidade de 50 escudos, argumentando que não viveria mais de dois ou três anos. Acordo fechado e assinado, Chicot ia todo mês encontrar a incansável senhora e pagar-lhe o prometido. Para desespero do negociante, ao cabo de três anos, a camponesa continuava gozando de excelente saúde, provocando a ira do albergueiro.

Chicot urdiu um plano macabro, esfregou as mãos e propôs à camponesa: "Puxa, por que não vem jantar em casa um dia, quando passar por Épreville? [...] Sabe, no meu albergue não vai pagar nada"2 (MAUPASSANT, 1979, p. 80). Convite aceito, o anfitrião não hesita em provocar indigestão em sua convidada:

O albergueiro, radiante, a tratou como uma dama, serviu-lhe frango, chouriço, tripas, borrego e repolhos com toucinho. Mas ela não comeu quase nada, comedida desde a infância, tendo vivido sempre de sopa e de uma crosta de pão com manteiga.

Chicot insistia desapontado. Ela não bebia também. Recusou o café.

Ele perguntou:

- A senhora aceitaria uma pequena dose.

- Ah! Isso sim, não digo não.

- Rosalie, traga da fina, a superfina, a fil-en-dix ${ }^{3}$ (MAUPASSANT, 1979, p. 81).

Como Magloire não era afeita aos prazeres da mesa, Chicot tentou, com sucesso, atraí-la para os efeitos do álcool. O albergueiro serviu-lhe ainda duas vezes e, a partir desse dia, passou a lhe presentear regularmente com garrafas dessa fortíssima bebida. Magloire passou a ser vista embriagada pela cidade e, em um dia de inverno, foi encontrada caída na neve, morta.

A aleivosia do camponês ao propor o jantar toca as raias da impostura, afinal ele oferece um menu suculento e copioso, digno de um convidado de honra.

O diálogo à mesa limita-se a perguntas e respostas estereotipadas. O caráter limitado e oco da conversa contrasta com a opulência dos pratos servidos. A única frase dita com entusiasmo e ênfase é dirigida à empregada Rosalie, o grito que ecoa pelo albergue exprime o sentimento da potencial vitória sobre a vítima. Não seria exagerado afirmar que, se a mesa consiste, tanto na cultura francesa

\footnotetext{
2 Para alguns contos do autor, aproveitei a tradução de Amilcar Bettega (2009). As demais citações de contos e textos críticos foram traduzidas por mim.

3 Aguardente muito forte.
} 
quanto em muitas outras, lugar privilegiado para demonstrações de afeto e de amizade, pode transformar-se igualmente em espaço para perfídias.

Armar cilada ao outro "ganhando-lhe pelo estômago" também ocorre em "Saint Antoine" (1883) - que faz parte da temática da guerra. Em seus contos consagrados à convivência forçada entre soldados alemães e a população francesa, após a humilhante derrota do exército imperial, em 1870, para os prussianos, e a consequente ocupação de parte do país pelos invasores, apresentam-se diversas situações nas quais a alimentação desempenha papel essencial nas tensões entre vencido e vencedor.

Como era regra durante a ocupação dos alemães, as famílias deveriam acolher ao menos um soldado. Em contrapartida, os militares auxiliavam com tarefas domésticas. Saint Antoine recebeu "seu" prussiano e passou a lhe servir alimentos de forma exagerada, além de embriagar-lhe com fil-en-dix. Saint Antoine passeava na cidade com o soldado, a quem apelidara de "porco" e, aonde ia, pedia que servissem algo ao companheiro:

Tomara o hábito de fazer com que oferecessem de comer a seu porco em todos os lugares aonde iam. Era o grande prazer, o grande divertimento de todos os dias: "Deem-lhe o que quiserem, ele engole tudo". E então ofereciam-se ao homem pão e manteiga, batatas, guisado e também linguiças, o que provocava ditos como: "É da sua, e de qualidade" (MAUPASSANT, 2009, p. 221).

O momento das refeições pode, ainda, propiciar ocasião para um diálogo repleto de platitudes e lugares-comuns. É o caso de Em família (1881) (MAUPASSANT, 1974, p. 193-218). Aqui o pequeno burguês Caravan, funcionário de repartição pública por mais de três décadas, vive com a esposa e os dois filhos em um modesto apartamento. Sua mãe, de 90 anos, reside em um andar acima do seu. A idosa é vítima de uma síncope que dura 24 horas, todos acreditam que está morta e as providências são tomadas para o enterro e demais formalidades. Durante esse período, a velha senhora escuta as discussões em torno da modesta herança que deixara. Logo após a constatação de sua suposta morte pelo médico, a nora da "defunta" insiste para que o clínico fique para jantar. Durante a refeição:

Repetiram o potage frio. O sr. Chenet tinha solicitado mais uma porção. Apareceu, em seguida, um prato de dobradinha à moda de Lyon que exalou um perfume de cebola e do qual a sra. Caravan hesitou em experimentar. "É excelente", disse o doutor. Ela sorriu "Não é?".

Quando o saladeiro apareceu repleto de macarrão, o doutor murmurou: "Caramba! Eis uma coisa boa." [...] O sr. Chenet lembrou o amor de Rossini por essas iguarias italianas; então, de repente: "Olha! Isso rima; poderíamos começar uma peça em verso:

O maestro Rossini

Gostava de macaroni..." (MAUPASSANT, 1974, p. 202, 203).

Fica patente aqui o colóquio iníquo entre a senhora Caravan e o médico. As observações deste são de uma banalidade a toda prova. Pensando na herança da sogra, a anfitriã mal presta atenção à conversa. O convidado, por seu turno, aproveita o jantar sem cerimônia e sem deferência alguma pela situação. A propósito, Geneviève Sicotte, autora da tese Les scènes de repas dans le roman de la seconde moitié $d u X I X^{e}$ siècle, tece um comentário relativo ao romance Éducation 
Sentimentale, de Flaubert, mas que, sob vários aspectos, contribui para refletirmos sobre os diálogos à mesa nos contos de Maupassant:

A enumeração rabelaisiana das modalidades de conversas à qual se refere o narrador flaubertiano reduz a palavra à sua dimensão grotesca: nas refeições se escutam apenas "ditos espirituosos, trocadilhos, palavras com duplo significado, cumprimentos e vulgaridades" [...] essas arengas de mesa são o sinal da adesão dos comedores a lugares-comuns insignificantes, mas sobretudo de sua participação a uma comunidade ridícula e detestável (SICOTTE, 1997, p. 138).

Seja no século XIX, seja em nossa época, basta reunirmos um grupo à mesa durante o almoço ou o jantar e presenciaremos a obediência a certos códigos. A necessidade de ser agradável, ser um bom contador de casos, espirituoso, assim como o cálculo de escolher o tema da conversa. Não por acaso, o momento da refeição em geral é rico para esmiuçar intenções ocultas que inspiram palavras e atos das pessoas e também das personagens.

\section{Racionamento, Ausência de apetite e FOME}

Se a mesa propicia o convivio deleitoso, se é o local das trivialidades e superficialidades, das histórias e dos ditos chistosos, pode, igualmente, ser o espaço do silêncio constrangedor. Em "Ceia de Natal” (1882), o narrador passava temporada na Normandia, hospedava-se na casa de um primo e soube que o senhor Fournel, muito idoso, havia falecido e então foi, com seu parente, visitar os familiares do defunto no horário da ceia. Ao entrarem na modesta residência, encontraram o filho de Fournel com sua esposa. A melancolia da cena não parece provocada pelo luto, mas sim pela indiferença do casal ao que se passava ao redor. O narrador nota a forma mecânica de seus gestos:

Tristes, com ar aflito e a face rude dos camponeses, comiam gravemente sem dizer palavra. Em um único prato, disposto entre eles, um grande pedaço de chouriço sobressaía de seu vapor pestilento. A intervalos regulares, eles arrancavam uma porção com a ponta de suas facas, esmagavam-no sobre o pão cortado em pedaços, depois mastigavam com lentidão.

Quando o copo do homem esvaziava, a mulher, pegando o jarro de sidra, o preenchia (MAUPASSANT, 1974, p. 339).

Em "A mãe Sauvage" (1884), uma senhora camponesa abriga quatro soldados. Ela recebe uma carta noticiando a morte do filho. Passa, então, a refletir sobre o que fazer. Solicita, em seguida, o nome completo e o endereço dos rapazes e passa a urdir seu plano sinistro para vingar-se:

Ela sentou-se à mesa com seus prussianos, mas não tinha vontade de comer, nem mesmo um pedacinho. Eles devoraram o coelho sem se preocupar com ela. Ela os observava de lado, sem falar, amadurecendo uma ideia, e o rosto de tal forma impassível que eles não perceberam nada (MAUPASSANT, 1991, p. 156).

Nas histórias sobre os camponeses da Normandia, as cenas de refeições ora expõem diálogos triviais, ora revelam o silêncio de seres rudes, extenuados da labuta diária. Em seu artigo "Manger toscan, manger normand", Graziella Farina Scarpa (2005, p. 196) analisa as coletâneas Contes de la Bécasse, de Maupassant, e Veglie di Neri, do escritor italiano Renato Fucini, e observa que: 
Como observadores escrupulosos, Maupassant e Fucini nos lembram que a refeição é melhor e mais abundante na cidade que nos campos e que o regime predominante na roça é, sobretudo, o da privação. Nesse sentido, vários contos dos Contes de la bécasse, mas sobretudo dos Veglie di Neri são, antes de tudo, "contos da fome".

De fato, a fome assombra as personagens de inúmeros contos de Maupassant, e as narrativas tratando da guerra evocam essa questão de forma incisiva. Em "Dois amigos" (1883), dois apreciadores da pesca reencontram-se, por acaso, e pretendem desfrutar do hobby comum. Acabam, no entanto, sendo presos pelos alemães, que suspeitam de traição. O incipit remete à penúria parisiense: "Paris estava cercada, faminta e agonizante. Os pardais eram cada vez mais raros nos telhados, e os esgotos se esvaziavam. Comia-se qualquer coisa" (MAUPASSANT, 2009, p. 191).

A tradução de Amilcar Bettega para o português, embora muito boa e cuidadosa, não resgatou o verso alexandrino da primeira frase: "Paris était bloqué, affamé et râlant" (MAUPASSANT, 2009, p. 107).

Lembremos que, antes de tornar-se contista renomado, Maupassant dedicou-se à poesia. Seu volume Des vers (Versos) foi publicado no mesmo ano que "Bola de Sebo" (1880). Notamos no incipit de "Dois amigos", por meio de gradação ascendente, a derrota e seus corolários: "cercada", "faminta" e "agonizante". Em seguida, divisamos a precariedade da vida na capital e a fome que surpreendeu a população carente. Não se trata aqui de ficção. Nesse período, em momentos desesperadores, comiam-se pardais e até ratos. Vale transcrever aqui o comentário de Louis Forestier sobre o início do conto:

A primeira frase do texto é um alexandrino. O fato é raro em Maupassant que possui de forma muito aguda o sentido da prosa. Estou inclinado a pensar que o escritor faz piscadela ao leitor aludindo, sob forma paródica, à lembrança de L'Année terrible. Este volume de Victor Hugo tinha aparecido em 1872. Todo mundo conhecia a Lettre à une femme que continha este verso: "comemos cavalo, rato, urso e asno" (MAUPASSANT, 1974, p. 1512).

Os animais do Jardim das Plantas desapareceram. Edmond de Goncourt comentou, em seu diário no dia 21 de janeiro de 1871, que uma moça o seguia na Rua Saint Nicolas e, logo que teve oportunidade, disse-lhe ao ouvido: "O senhor gostaria de subir ao meu apartamento, por um pedaço de pão?" (GONCOURT, 1890).

Ainda no conto "Dois amigos", vale notar um procedimento empregado com frequência por Maupassant que poderiamos denominar "antecipação". Trata-se de anunciar, por intermédio de uma imagem, da fala de uma personagem ou de uma alusão qualquer, o destino do protagonista que será esclarecido no fim da leitura. Antes de serem presos e fuzilados, os dois pescadores dialogam:

Morissot balbuciou: "E se nós fôssemos até eles [os prussianos]?"

O sr. Sauvage respondeu, com aquele sarcasmo parisiense que, apesar da situação, reaparecia:

- Ofereceríamos uma fritada para eles (MAUPASSANT, 2009, p. 199).

Somente ao terminar a última linha, o leitor compreenderá essa passagem. Tal forma de comunicar sutilmente o desfecho mantém a atenção do leitor até o fim e convida-o a decifrar essas alusões aparentemente anódinas. 


\section{"NA GUERRA COMO NA GUERRA"}

Quando o conflito foi deflagrado, os franceses ignoravam a diferença abissal entre seu país e a Prússia, verdadeira potência militar. Outra razão favorável aos alemães era a motivação: "Sobretudo, a Prússia tinha um moral extraordinário e os demais países alemães que se uniram a ela no combate tinham consciência de conduzir uma luta 'nacional' para a constituição de uma nação unida” (MIQUEL, 1976, p. 399). Após um incidente diplomático, a França declarou guerra em 18 de julho de 1870, sem ter preparo algum.

O escritor foi surpreendido com o conflito aos 20 anos e logo mobilizado para servir nos arredores de Rouen. O interesse de Maupassant pelo assunto deve-se mais à marca incisiva que a guerra lhe deixou do que a uma voga, por assim dizer, de uma literatura destinada ao tema.

Se existem semelhanças entre o autor normando e seus pares quando abordam a derrota francesa, as disparidades são mais consideráveis, já que essa página da História o amargurou de tal forma que uma parte de sua concepção da vida e dos homens pode ser considerada tributária desse período.

O pessimismo maupassantiano teve origem, ao menos em parte, nessa experiência de sua juventude, sendo, posteriormente, recrudescido pela leitura de Schopenhauer. O discípulo de Flaubert descobriu, ao longo dos anos 1870 e 1871, além de uma fonte para várias narrativas passiveis de interessar aos leitores, um suporte para suas convicções filosóficas. Antibelicista contumaz, em crônica para o Gil Blas (11 de dezembro de 1883), afirma:

Quando se fala de antropófagos, sorrimos com orgulho proclamando nossa superioridade sobre esses selvagens. Quais são os selvagens, os verdadeiros selvagens? Aqueles que lutam para comer os vencidos ou aqueles que lutam para matar? [...] simplesmente para matar? [...] (MAUPASSANT, 1991, p. 244).

Em "A aventura de Walter Schnaffs" (1883), há um raro momento em que se esboça benevolência por um soldado prussiano, pois se trata de um desertor. Eis o começo da narrativa:

Desde sua entrada na França com o exército invasor, Walter Schnaffs julgava-se o mais infeliz dos homens. Era obeso, caminhava com dificuldade, ofegava bastante e sofria terrivelmente dos pés, que eram muito chatos e muito gordos. Além disso, era pacífico e benevolente, de forma alguma sanguinário, pai de quatro filhos que adorava e casado com uma moça loura, de cujos carinhos, cuidados e beijos, ele sentia saudade todas as noites, desesperadamente. Gostava de acordar tarde e deitar cedo, de comer com calma a boa comida e de beber nas cervejarias (MAUPASSANT, 2009, p. 233).

A obsessão do soldado trânsfuga é tornar-se prisioneiro para matar a fome. A condescendência do narrador, porém, ocorre eivada de ironia. O som produzido pela pronúncia do nome Schnaffs, por exemplo (assim como do refrigerante "Schweppes"), remete à caricatura que os franceses fazem da língua alemã quando imitam o vizinho de além-Reno. Embora aqui o inimigo seja inofensivo, o narrador reforça seus traços grosseiros e ridículos. Há, possivelmente, também ironia na escolha da palavra "aventura" do título, que remete um pouco à imagem de um herói romântico que enfrenta dificuldades até ser recompensado pela bravura. Ora, o alemão desertor constitui o arquétipo do anti-herói: fraco 
e medroso. Mas o fato de ter abandonado o exército, de não querer mais lutar, de passar para o "lado francês", mesmo como prisioneiro, desperta a simpatia do leitor.

Além do tema da invasão apresentado logo nas primeiras linhas, a angústia do futuro prisioneiro é anunciada também logo no início. Raramente, ao menos nos contos de guerra de Maupassant, os inimigos são apresentados por seus nomes. Por isso, é bastante significativo que o autor o faça aqui. Isso não indica somente que se trata do protagonista, mas sugeriria certa simpatia do narrador em relação ao inimigo, ressaltando-se o caráter humano do soldado.

Separado de seu grupo, refletindo sobre como seria a melhor maneira de render-se, o soldado, devastado pela fome, surge à janela de uma mansão exatamente no momento em que empregados se preparavam para iniciar uma suculenta refeição. Ao reconhecerem o capacete típico do exército prussiano, desesperam-se e escondem-se sem perceberem o estado de fraqueza do suposto invasor. Diante da cozinha vazia, o soldado invade-a e inicia seu banquete animalesco:

Walter Schnaffs sentou diante de um prato que tinha ficado intacto e começou a comer. Comia enchendo a boca, como se tivesse medo de ser interrompido cedo demais, de não poder engolir o suficiente. Metia com as duas mãos grandes porções de comida na boca, que se abria como um alçapão; e bolos de alimentos desciam um atrás do outro em seu estômago, inchando-lhe a garganta na passagem. Por vezes ele se interrompia, prestes a rebentar como um tubo cheio demais. Então apanhava uma jarra de sidra e desobstruía o esôfago como quem lava um cano entupido.

Limpou todos os pratos, todas as travessas e todas as garrafas; depois, farto de líquido e de comida, imbecilizado, vermelho, sacudido por soluços, o espírito confuso e a boca pastosa, desabotoou o uniforme para respirar melhor, incapaz de dar um passo. Os olhos se fechavam, os pensamentos se entorpeciam; pousou a testa pesada sobre os braços cruzados em cima da mesa e suavemente perdeu a noção das coisas e dos fatos (MAUPASSANT, 2009, p. 238).

Expressões como "enchendo a boca", "engolir o suficiente", "porções de comida", "bolos de alimento", "prestes a rebentar como um tubo", assim como as palavras "estômago", "esôfago", "garganta" não costumam fazer parte de descrições de festins gastronômicos e conferem ao texto um caráter histriônico, grotesco. Em vez de explanações sobre fragrância, odores, tessituras, ingredientes e delicadeza do paladar, há o desespero de comer o máximo possivel antes que seja tarde demais. Não há a fase de mastigar, degustar, saborear, mas simplesmente engolir.

O aspecto cômico dessa representação do soldado já se insinuara no início da narrativa, quando lemos a respeito do seu ódio pelas armas "[...] sobretudo das baionetas, sentindo-se incapaz de manejar essa arma rápida com destreza suficiente para defender a sua enorme barriga" (MAUPASSANT, 2009, p. 233).

$\mathrm{O}$ ato de comer nos contos de guerra consiste em momento privilegiado para trazer à tona diferenças entre o bom gosto francês, sua arte de bem servir, de receber com cortesia, de desfrutar do prazer com vagar, e o rude soldado alemão, representando o antípoda da elegância. Nesse sentido, "Mademoiselle Fifi" (1882) (MAUPASSANT, 1974, p. 385-397) desvenda inúmeros momentos de confrontação entre esses dois países no que diz respeito ao savoir vivre. 
É necessário esclarecer que o sarcasmo do contista em relação aos alemães não se explica por um julgamento preconcebido, pois o alvo é o prussiano na condição de militar. Para Maupassant, aliás, o simples status de soldado favoreceria o comportamento arrogante e brutal. O início de "Mademoiselle Fifi" traduz a incivilidade dos invasores oposta ao bom gosto dos aristocratas que deixaram sua mansão às pressas. Um comandante prussiano lia confortavelmente sentado e com as botas sobre o mármore da lareira. O leitor depara com peças, possivelmente preservadas por várias gerações, manchadas por bebidas, queimadas por licores, destruídas, enfim, por mero passatempo de soldados ociosos.

Mas, no que diz respeito a todos os clichês que envolvem as refeições, o conto "Bola de Sebo" representa uma das realizações mais primorosas de Maupassant. A prostituta Elisabeth Rousset integra o grupo de dez passageiros que obtiveram o livre conduto para deixar Rouen em direção ao Havre. A diligência parte em uma manhã de inverno. Além da senhorita Rousset, viajam o casal de atacadistas de vinho senhor e senhora Loiseau; o senhor Carré-Lamadon, homem estabelecido no ramo de algodão, e sua esposa; o conde e a condessa Hubert de Bréville; duas religiosas e o democrata solteiro Cornudet.

Elisabeth Rousset, que recebera o apelido de Bola de Sebo em virtude de seu corpo roliço, tem atitude reservada, empolga-se somente quando falam dos inimigos. Ela se recusou a receber um soldado em sua casa e preferira fugir. A viagem é mais longa do que esperavam. Ao cabo de algumas horas, a fome surpreende os viajantes, mas não havia albergue à vista. Todos se recriminavam de não ter levado mantimentos:

No entanto Cornudet tinha um cantil cheio de rum; ofereceu: recusaram friamente. Apenas Loiseau aceitou um golezinho e, devolvendo o cantil, agradeceu: "Tem-se que reconhecer que isso é bom, esquenta e engana o estômago". O álcool deixou-o bem-humorado, e propôs que fizessem como no navio da canção: comer o mais gordo dos passageiros. Aquela alusão indireta a Bola de Sebo chocou os bem-educados (MAUPASSANT, 2009, p. 43).

Reconhecemos aqui também um procedimento de "antecipação", essa referência à prostituta não é sem relação com o desfecho do conto. Na diligência em direção ao Havre, desenrola-se o conhecido episódio da refeição copiosa e carinhosamente preparada por Bola de Sebo:

Enfim, às três horas, quando se encontravam no meio de uma planura interminável, sem uma só aldeia à vista, Bola de Sebo se abaixou de repente e puxou de baixo do banco um grande cesto coberto por um guardanapo branco.

Tirou primeiro um pratinho de faiança, uma fina taça de prata, depois uma grande terrina com dois frangos trinchados e conservados na própria gordura; e percebia-se ainda uma porção de coisas boas enroladas dentro daquele cesto: patês, frutas, guloseimas, alimentos preparados para uma viagem de três dias, para não ter que recorrer às cozinhas dos albergues. Quatro gargalos de garrafas despontavam entre os embrulhos de comida. Ela pegou uma asa de frango e, delicadamente, pôs-se a comê-la com um desses pãezinhos que na Normandia a gente chama "Régence".

Todos os olhares dirigiam-se para ela. Em seguida, o cheiro se espalhou, dilatando as narinas, fazendo vir às bocas uma saliva abundante, com uma contração 
dolorosa da mandíbula abaixo das orelhas. O desprezo das senhoras por aquela moça tornava-se feroz, como um desejo de matá-la, ou de jogá-la sob as rodas do carro, na neve, ela, a sua taça, seu cesto e sua comida (MAUPASSANT, 2009, p. 44).

Bola de Sebo, a cidadã de status social sem prestígio algum, com quem mal trocam palavras, justamente ela será a presença providencial na diligência. Quando cerimoniosamente, com muita deferência, oferece aos viajantes sua abundante refeição, alguns aceitam de pronto. O emprego da metonímia, na descrição que segue, mostra sobejamente a grotesca atitude de seus companheiros:

As bocas se abriam e se fechavam sem parar, engoliam, mastigavam, devoravam ferozmente. Loiseau, no seu canto, trabalhava duro, e em voz baixa incentivou a mulher a fazer o mesmo. Ela resistiu bastante tempo, mas, após uma crispação que lhe percorreu as entranhas, cedeu. Então o marido, arredondando a frase, perguntou se sua "encantadora companheira" lhe permitia oferecer um pedacinho à sra. Loiseau. "Mas claro, certamente”, respondeu Bola de Sebo, com um sorriso amável, estendendo-lhe a terrina (MAUPASSANT, 2009, p. 44-45).

O conde e a condessa, assim como o senhor e a senhora Carré-Lamadon, menos afoitos, não ousaram insinuar que estavam com fome e:

[...] sofriam este odioso suplício que conservou o nome de Tântalo. De repente, a jovem senhora do empresário soltou um suspiro que fez com que todos se voltassem para ela; estava tão branca quanto a neve lá fora; seus olhos se fecharam, a cabeça pendeu: tinha desmaiado (MAUPASSANT, 2009, p. 45).

Graças a uma taça repleta de Bordeaux, a senhora Carré-Lamadon recuperou as forças. Finalmente, os quatro viajantes que ainda jejuavam aceitaram de bom grado participar do piquenique improvisado.

Ao chegarem a Tôtes, o oficial alemão que se encontra no albergue onde o grupo pernoitaria, ao saber da profissão de Bola de Sebo, decide solicitar seus favores. Ela recusa de forma veemente. Seus companheiros, ao saberem do atrevimento do alemão, ficam indignados e até se solidarizam com ela. Ocorre que todos são impedidos de partir diante da obstinada resistência de Bola de Sebo.

A indignação dos companheiros de viagem da cortesã foi passageira. No dia seguinte, já começaram a tratá-la com frieza e passaram a empregar diferentes estratagemas a fim de convencê-la, a começar pelo elogio das qualidades físicas do oficial.

Notamos a maestria do narrador ao esboçar a separação que situará em dois campos distintos Bola de Sebo e seus companheiros. De fato, um dos momentos-chave da narrativa constitui o longo rol de argumentos empregados pelos viajantes para persuadi-la.

A passagem que começa com "Então conspiraram" até "[...] no país dele" representa verdadeira obra-prima da descrição da perfidia. Os atores da manobra, como sabemos, são respeitáveis cidadãos de Rouen. Mesclando exemplos históricos, mitos e lendas, vieram à tona Judite e Holofernes, Lucrécia com Sextus, Cleópatra, além de inúmeras mulheres que usaram o próprio corpo como campo de batalha. Convidada a contribuir com modelos religiosos, uma das freiras cita Abraão. As referências religiosas têm grande peso e ela cede, enfim, à exigência do oficial. 
O grupo poderá prosseguir a viagem. Na diligência a caminho do Havre, começa uma animada conversa. Todos levavam algum alimento para o trajeto, exceto Bola de Sebo:

Ninguém a olhava, não pensavam nela. Sentia-se afogada no desprezo daqueles polidos tratantes que a tinham sacrificado primeiro e a rejeitado em seguida, como uma coisa imunda e inútil. Então pensou em seu grande cesto cheio de coisas boas que eles tinham gulosamente devorado, em seus dois frangos reluzentes de gordura, nos patês, nas peras, nas quatro garrafas de bordeaux, $e$ seu furor caindo de súbito, como de uma corda esticada demais que se rompe, ela se sentiu prestes a chorar (MAUPASSANT, 2009, p. 67-68).

A generosa prostituta, de posição política bem definida e firmes convicções religiosas, além de ser inescrupulosamente sacrificada pelo grupo, é rapidamente esquecida. Em toda a narrativa, sugere-se o contraste entre ela e os demais personagens.

\section{Angústia PELO COMPORTAMENTO DOS hOMENS}

Nos contos evocados, seja tratando da guerra, do camponês, da cortesã patriota, do militar inescrupuloso ou do aristocrata pedante, notamos um profundo desencanto pelo homem, independentemente da classe social e da função que ocupa. Nessas narrativas, nota-se, com frequência, descompasso entre o pensamento das personagens e suas atitudes. Seja por meio do narrador onisciente, seja optando pela narração em primeira pessoa, a análise do comportamento humano é impiedosa.

Em algumas passagens, a reminiscência do mito grego relativo ao rei da Lídia é inevitável. Tântalo, filho de Zeus, quis verificar se os ocupantes do Olimpo eram mesmo oniscientes. Para tanto, rouba néctar (bebida que eternizava a vida) e ambrosia. Convida os deuses para um banquete e serve-lhes um prato preparado com a carne do próprio filho Pélops. O crime foi descoberto e Tântalo foi condenado a ficar submerso até o peito em um rio. Cada vez que tentava alcançar uma fruta que pendia de uma árvore, o vento lançava os ramos para longe. Da mesma forma, a água desaparecia quando se debruçava para tentar bebê-la.

Nas histórias do contista normando, ora as personagens consomem pouco, por costume ou economia, ora preparam refeições copiosas a fim de manipular o outro. Há ainda a imposição do terrivel suplício de Tântalo como no caso de "Bola de Sebo".

Graças à precisão de suas descrições, aos episódios magnificamente construídos, aos pormenores aparentemente insignificantes, Maupassant desmitifica nossas aparentes boas intenções. Tanto em situações do cotidiano quanto em circunstâncias excepcionais (como os períodos de guerra), o ato de alimentar-se e tudo que o envolve revela o que há de mais pérfido no ser humano.

\section{From the SUPPlice of tantalo to THE WILD GLUTtony: EVocations of THE SHORT Stories by GUY DE MaUpassant}

Abstract: In Guy de Maupassant's short stories, descriptions of lunch, dinner, suppers, and picnics unleash fundamental episodes in narratives. They propose, frequently, elements for reflections on the characters, their desires and 
fears. They also evoke their intentions and their maneuvers to manipulate the other. In addition to the realistic effect intended by the author, as indeed many writers of the second half of the nineteenth century. Everything that happens "at the table", in the stories of the Norman storyteller, deserves an attentive questioning of the reader. In this article, it is a question of reflecting on the calculation, the duplicity, the constant simulation that guides the customs and the attitudes of peasants, bourgeois and aristocrats from the episodes involving meals. We will covers of different themes, but we will emphasize the texts dedicated to the Franco-Prussian War, from 1870 to 1871.

Keywords: Guy de Maupassant. Meals. Short stories. Descriptions. Franco-Prussian War.

\section{REFERÊNCIAS}

BROCHIER, J.-J. Maupassant: une journée particulière $1^{\text {er }}$ février 1880. Paris: Éditions J. C. Lattès, 1993.

GONCOURT, E. Journal des Goncourt: mémoires de la vie littéraire, $2^{\mathrm{e}}$ série, v. 1, tome IV (1870-1871). Paris: Bibliothèque Charpentier, 1890. 373 p. Disponivel em: http://obvil.sorbonne-universite.site/corpus/critique/goncourt-edmond_ journal-04/. Acesso em: maio 2020.

MAUPASSANT, G. Contes et nouvelles. Texte établi et annoté par Louis Forestier. Paris: Galliamard, 1974. t. I. (Bibliothèque de la Pléiade).

MAUPASSANT, G. Contes et nouvelles. Texte établi et annoté par Louis Forestier. Paris: Gallimard, 1974. (Bibliothèque de la Pléiade).

MAUPASSANT, G. Contes et nouvelles. Édition de Louis Forestier. Paris: Gallimard, 1979. t. II. (Bibliothèque de la Pléiade).

MAUPASSANT, G. Romans. Édition établie par Louis Forestier. Paris: Gallimard, 1987. (Bibliothèque de la Pléiade).

MAUPASSANT, G. Boule de suif: et autres récits de guerre. Commentaires de Claude Aziza et Pascaline Mourier-Casile. Paris: Presses Pocket, 1991.

MAUPASSANT, G. Contes de la Bécasse. Édition présentée, annotée et commentée par Évelyne Amon. Paris: Éditions Larousse, 2008. (Petites Classiques).

MAUPASSANT, G. 125 contos de Guy de Maupassant: escolhidos por Noemi Moritz Kon e traduzidos por Amilcar Bettega. São Paulo: Companhia das Letras, 2009.

MIQUEL, P. Histoire de la France. Paris: Fayard, 1976.

SCARPA, G. F. Manger toscan? Manger normand? Représentation et rôle de la nourriture dans Les Contes de la bécasse de Maupassant et Le Veglie di Neri de Renato Fucini. In: Le populaire à table: Le boire et le manger aux $\mathrm{XIX}^{e}$ et $X X^{e}$ siècles. Études réunies par Mireille Piarotas et présentées par Pierre Charreton. Saint-Étienne: Publications de l'Université de Saint-Étienne, 2005. p. 191-203. SICOTTE, G. Les scènes de repas dans le roman de la seconde moitié du XIXe siècle français. Montréal: Université de Montréal, 1997.

SMEETS, M. Huysmans, Maupassant et Schopenhauer: note sur la métaphysique de l'amour. In: BEHAMOU, N. Guy de Maupassant. Études réunies par Noëlle Benhamou. Amsterdam; New York: Rodopi, 2007. p. 21-31. 